\title{
A Study of NCAA Gambling Prevention Videos on Gambling Perceptions Within a NCAA Division II Baseball Team
}

\author{
Timothy Mowrer, Jeffrey W. Wimer, Rebecca J. Mowrey, \\ and Daniel F. O'Neill \\ Millersville University
}

\begin{abstract}
The purpose of this study was to investigate gambling attitudes among collegiate baseball players. We wanted to know if online educational videos developed by the NCAA would be successful in altering gambling attitudes and behaviors. A Randomized Controlled Trial (RCT) with a pretest-posttest design was conducted for this study. Subjects included a convenience sample of 33 baseball studentathletes from a NCAA Division II University in the mid-Atlantic region. Gambling attitudes and behaviors of collegiate baseball student-athletes were determined through survey questions and the administration of the South Oaks Gambling Screen. Findings indicated that baseball student-athletes participated in a variety of gambling activities, and that NCAA educational videos are moderately successful in altering student-athletes' attitudes toward gambling. This study is important for college and university athletics departments as they work to counter the progambling messages that student-athletes receive.
\end{abstract}

Keywords: gambling, college baseball, student-athletes, NCAA

\section{Gambling in United States}

Gambling is ubiquitous in the United States and has emerged as an activity that is widely accepted by American society (Stinchfield, Hanson, \& Olson, 2006). Previous studies have found that gambling is a common activity that people enjoy (Cross \& Vollano, 1999; Burger, Dahlgren, \& MacDonald, 2006; Engwall, Hunter, \& Steinberg, 2004; Figone, 2012; Seifried, Krenzelok, Turner, \& Brett, 2009). A plethora of factors have contributed to the expanding normative nature of gambling in our society including the increased legalization of gambling, technology's influence on the accessibility of gambling opportunities, formalized ties between sports organizations and gambling entities, and the mass media's glorification of

Mowrer, Wimer, and Mowrey are with Wellness and Sport Sciences, Millersville University, Lancaster, Pennsylvania. O'Neill is with Counseling and Human Development at the same university. Address author correspondence to Timothy Mowrer at tmowrer@cacsports.com. 
the activity (Ellenbogen, Jacobs, Derevensky, Gupta, \& Paskus, 2008; National Collegiate Athletic Association, 2013a; Paskus \& Derevensky, 2012; Reib, 2011; Seifried et al., 2009). These influences have also led to confusion among many Americans as to what constitutes legal and illegal gambling (Drayer \& Sparvero, 2012; National Collegiate Athletic Association, 2013a). This is particularly true when it comes to wagering on sports. The National Gambling Impact Study Commission (NGISC) (1999), a comprehensive study of gambling and gambling addiction in the U.S., found that many Americans are unaware that wagering on sports is illegal in most locations across the country.

The increased popularity of gambling activities like fantasy sports has further blurred the lines of the legality of gambling in the United States (Drayer \& Sparvero, 2012). Betting on fantasy sports is legal according to U.S. federal law. The Unlawful Internet Gambling and Enforcement Act of 2006 (UIGEA), which set the legal standards for online gambling, made an exception that included fantasy sports by deeming them games of skills rather than games of chance (Smith, 2012). Despite this law, the debate continues as to whether fantasy sports should be considered a form of sports gambling (Drayer \& Sparvero, 2012). This debate has intensified recently as the two largest fantasy sports companies, DraftKings and FanDuel, ramped up their advertising efforts spending millions of dollars over several months to coincide with the start of the 2015 NFL season (Belson \& Drape, 2015; Drape \& Williams, 2015). According to data from iSpot.tv, which tracks national television ads, the two companies have combined to spend over $\$ 200$ million on national ad campaigns since January 2015, including over \$27 million for approximately 8,000 television ads during the first week of the NFL season (Belson \& Drape, 2015; Kludt, 2015). The increased marketing efforts of DraftKings and FanDuel have prompted lawmakers to investigate whether these types of fantasy games are stretching the limits of the UIGEA exception which enabled them to operate (Drape \& Williams, 2015). New York, Florida and Nevada regulators have ordered daily fantasy sports companies to suspend operations. Nearly a dozen other states are considering some form of fantasy sports legislation (Bogdanich, Drape, \& Williams, 2015).

Gambling among college students, particularly student-athletes, is an issue that requires further investigation and research. As legalized gambling continues to expand and become more socially acceptable, colleges and universities need to be aware of potential risk factors involved with gambling behaviors occurring on campuses across the country. The purpose of this study was to examine if NCAA Division II collegiate baseball student-athletes were at risk for developing negative gambling behaviors, and if the implementation of an NCAA-produced video educational intervention program would be successful in altering gambling attitudes and behaviors.

A variety of factors contribute to the need for additional research on collegiate baseball student-athletes' gambling behaviors and attitudes. These reasons include the propensity of male student-athletes to gamble (and to develop problem gambling behaviors), an increasing societal acceptance of gambling as a common recreational activity, and that collegiate baseball student-athletes gamble at higher rates than the majority of other sports (Ellenbogen et al., 2008; Paskus \& Derevensky, 2012). Moreover, researchers have indicated a need for increased education on the potential dangers of gambling, specifically among college student and student-athlete populations (Engwall et al., 2004; Seifried et al., 2009). 


\section{Gambling Addiction}

Gamblers are classified by several categories. Those who experience serious responses to gambling are labeled as compulsive, problem, or disordered gamblers (Shaffer, Hall, \& Vander Bilt, 1999). Gambling activities are considered problematic when an individual experiences negative consequences such as feelings of guilt, gambling more than anticipated, and/or sacrificing time from school or work (Engwall et al., 2004). Disordered gamblers are often preoccupied with gambling activities. They often use gambling as a way to escape from problems when experiencing feelings of distress, and frequently try to make up for, or "chase" their gambling losses (National Center for Responsible Gaming, 2013). The American Psychiatric Association defines gambling disorder as: "Persistent and recurrent problematic gambling behavior leading to clinically significant impairment or distress" (American Psychiatric Association, 2013). Volberg (1996) suggests that roughly $2 \%$ of the U.S. population suffer from problems associated with gambling. A more recent study by Williams and Volberg (2012) found that the problem gambling rate in the U.S. is $2.2 \%$.

\section{Gambling and Public Health Issues}

Public health research has discovered links between gambling and other healthrelated issues such as alcohol and drug abuse. Gambling has also been found to have addictive potential much like alcohol, drugs, and tobacco-related products (Engwall et al., 2004; LaBrie, Shaffer, LaPlante, \& Wechsler, 2003). In addition, research suggests that problem gambling among young adults is connected with other negative behaviors including unprotected sexual activity, eating disorders, and high rates of using alcohol, illicit drugs and tobacco (Engwall et al., 2004). Finally, gambling problems have been shown to negatively impact other facets of life, as they potentially threaten academic success, relationships, levels of self-esteem, health, finances, and future job prospects (Seifried et al., 2009).

The literature is consistent that there is an association between gambling and high-risk behaviors, particularly among male college students and student-athletes. While gambling is rarely spoken of in the same breath as other student health issues like alcohol and drug abuse, many similarities exist between these risk-taking behaviors (Huang, Jacobs, Derevensky, Gupta, \& Paskus, 2007; Lesieur, Cross, Frank, Welch, \& White, 1991).

\section{Gambling Among College Student-Athletes}

The increasing popularity of fantasy sports has created new opportunities for college-aged gamblers to fulfill their gambling desires (Drayer \& Sparvero, 2012). A 2012 NCAA study found that far fewer student-athletes consider fantasy football and other fantasy games to be gambling than in previous NCAA studies from 2004 and 2008. In addition, 57\% of male student-athletes and $41 \%$ of female student-athletes believe that sports wagering is an acceptable activity as long as they do not place wagers on their own sports. An even more startling statistic is that $59 \%$ of male student-athletes and $49 \%$ of female student-athletes think that 
they can consistently make money betting on sports (National Collegiate Athletic Association, 2013a).

Several studies have found that male student-athletes are more likely to develop gambling problems than nonathlete male college students. For example, Engwall et al. (2004) determined that students participating in either club or intercollegiate sports are significantly more likely to develop gambling problems than nonathletes. Similarly, among women, the rate of problem gambling and gambling disorder was higher for student-athletes $(7 \%)$ than nonathletes $(4 \%)$. Likewise, LaBrie et al. (2003) analyzed data from a sample of more than 10,000 college students and found that members of an intercollegiate sports team are more likely to gamble than those who do not play sports. Ellenbogen et al. (2008) concluded that studentathletes are three times more likely to be weekly gamblers, raising the concern that student-athletes with regular gambling habits are more likely to develop into problematic gamblers. Ellenbogen et al. (2008) also concluded that student-athletes with gambling problems may be aware that their behaviors pose potential threats to their athletic futures, and therefore may resist seeking help or treatment for fear of being exposed. In addition, male student-athletes who participate in high-profile sports such as baseball, basketball, and football are more prone to develop gambling problems (Ellenbogen et al., 2008).

Beginning in 2004, the National Collegiate Athletic Association (NCAA) has conducted studies surveying student-athlete gambling behaviors and attitudes. In the most recent NCAA study (2012), 11 sports were surveyed for male student-athletes and 11 sports were surveyed for female student-athletes. Of those surveyed, $25.7 \%$ of males and $5.2 \%$ of females stated that they had broken NCAA rules by betting money on sports (Paskus \& Derevensky, 2012). While golfers have consistently been the largest subgroup of college student-athletes who gamble on sports (Paskus \& Derevensky, 2012), baseball players reported gambling at higher rates than the majority of other sports such as basketball, football, ice hockey, tennis and wrestling. In addition, baseball players ranked among the top four sports in gambling rates in each of the three studies. (Paskus \& Derevensky, 2012).

Wagering on sports by student-athletes is a violation of NCAA rules (National Collegiate Athletic Association, n.d.). NCAA bylaws prohibit participation in any type of gambling activity that involves intercollegiate or professional athletics events including fantasy leagues, March Madness brackets, sports pools, and online sports wagers. If a student-athlete risks a material possession, such as an entry fee, for an opportunity to win something in return, it is a violation of NCAA sports wagering bylaws. Despite these bylaws, Ellenbogen et al. (2008) found that nearly one half of their sample of 20,739 NCAA student-athletes reported that they were unsure or unaware of NCAA gambling rules. And, in 2012, similar findings suggest that the respondents had received little information about NCAA gambling rules according to the NCAA gambling study report (Paskus \& Derevensky, 2012).

\section{Gambling Scandals in Sport}

Numerous gambling-related scandals involving college athletics have occurred over time. In 1951, 32 college basketball players from seven schools collaborated to manipulate the point margin of games in exchange for money, including the reigning National Invitational Tournament (NIT) and NCAA basketball champions 
from the City College of New York (Buckstaff, 2013; Goldstein, 2003). One of the largest-ever point-shaving scandals occurred in 1979 when four Boston College basketball student-athletes fixed nine games (Hohler, 2014). In 1996, Boston College was involved in another gambling scandal when 13 football players placed bets on college and professional sporting events, including two who bet against their own team (Moran, 1996). From 2004 through 2006, six University of Toledo football and basketball players were involved in a point-shaving scheme. The players received money and other items of value in exchange for inside information and game-fixing plots (Fish, 2009).

The most prominent gambling-related problems at the collegiate level tend to occur in basketball and football. However, other sports are not immune to the consequences of sports wagering. One prominent example from the sport of baseball occurred at the University of Maine. The Black Bears have a storied history as one of the oldest and most successful collegiate baseball teams. The program originated in 1881 and advanced to the College World Series seven times in the 1960s through the 1980s. In 1992, thirteen baseball players were found to be a part of a $\$ 10,000$ a-week gambling operation (Millman, 2002). A sophomore centerfielder for the Black Bears was arraigned in the scandal as being the bookmaker (Ginsburg, 2004).

Baseball at the professional levels has a long and troubling history with gambling. The most notorious examples include the Chicago Black Sox Scandal of the 1919 World Series and the Pete Rose betting scandal of the 1980s (Cassuto, 2011). More recently, a gambling scandal occurred in Japanese professional baseball. Three pitchers from the Yomiuri Giants of Nippon Professional Baseball were found to have wagered on games involving their own team in addition to Major League Baseball games and high school baseball games (Armstrong, 2015). Both the historical and contemporary gambling issues surrounding the sport of baseball highlight the need for additional research on the topic.

\section{NCAA and Professional Sports Leagues' Relationships With Gambling}

Professional sports leagues in the U.S. have a mixed bag of rules regarding gambling. There is no uniform approach between the leagues, as gambling restrictions vary from league to league. For example, MLB, NBA and NHL players are prohibited from playing fantasy sports that involve their respective leagues, while NFL players are permitted to play fantasy football (Lisk, 2015; Ozanian, 2015). Similarly, MLB, NBA and NHL players are permitted to legally wager on sports other than their own in Nevada, while the NFL has a strict antigambling policy that prohibits players from gambling on any sport (Chad, 2015; Frisaro, 2015; Levinson, 2015). Rules also differ between players and officials, with officials facing the strictest consequences for gambling. Professional athletes in all leagues are prohibited from placing illegal bets with bookmakers. In addition, they are permitted to attend casinos or race tracks on their personal time. (Florio, 2015; Frisaro, 2015). NFL and NBA officials, meanwhile, are only allowed to enter a casino or race track during the offseason (Florio, 2012; Sheridan, 2007).

The NCAA, major professional sports leagues, and lawmakers have opposed the expansion and further legalization of sports gambling. These organizations contend 
that legal and illegal sports wagering negatively impacts players, teams, and fans, and that mixing gambling with sports raises questions about the honesty and fairness of competition (Buckstaff, 2013). Cross and Vollano (1999) reported that over 100 NCAA student-athletes have been accused of participating in gambling-related activities including: point-shaving, betting, giving inside information to bookmakers, losing games on purpose, or altering the final score of games based on the odds makers betting lines. Since 1999, NCAA member institutions have reported 13 sports wagering violations that include wagering on fantasy sports leagues, March Madness pools, and college and professional sporting events (National Collegiate Athletic Association, 2014). In recent years, NCAA research has discovered an increase in the number and severity of sports gambling violations. Since August 2011, there has been an increase in fantasy league and sports pool violations among student-athletes (Paskus \& Derevensky, 2012).

Nevertheless, not all sport industry leaders agree with the professional sports leagues' and the NCAA's long-standing opposition toward legalized sports gambling. NBA commissioner Adam Silver has openly supported widespread legalized sports gambling. Writing an op-ed piece published in the New York Times, Silver proposed that Congress should enable States to allow gambling on professional sports, but also include new oversight regulations that include monitoring and reporting irregular betting-line movements. He states that new technologies will ensure betting is fair, and through improved education, the public should be permitted to gamble responsibility (Silver, 2014).

The financial incentives for major sports organizations to align themselves with the highly profitable and growing gambling industry cannot be understated. While the NCAA and the U.S. professional sports leagues have traditionally opposed legalized sports gambling, there is increasing evidence that attitudes about gambling are shifting. These changing societal views will necessitate the need for more education on the potential risks involved with sports gambling.

\section{Prevention Efforts}

It is vital for the sport management professional to recognize the potential impact that increased legalized gambling will have on problem gambling and gambling addiction rates in the United States, and particularly among the at-risk demographic of college male student-athletes. Understanding the appropriate strategies and techniques that may deter gambling practice is critical for the integrity of sport, as well as for the health and wellbeing of the student-athlete.

A 2012 NCAA study of approximately 23,000 student-athletes found that $71.5 \%$ of males and $75.9 \%$ of females at the Division I level had received information about NCAA rules and guidelines regarding gambling. Meanwhile, fewer than $60 \%$ of males and females in Divisions II and III reported receiving the same information on wagering rules (Paskus \& Derevensky, 2012). In addition, 19\% of males in Division I reported violating NCAA rules by wagering on sports in 2012, while $26 \%$ in Division II and 32\% in Division III reported these same infractions. For females, sports wagering rates for Division I, II and III were 3\%, 5\% and $7 \%$, respectively. These disparities are most likely due to variances in educating student-athletes about NCAA gambling rules and perceptions that these rules 
are merely an issue for Division I student-athletes (National Collegiate Athletic Association, 2013b).

Research conducted by the NCAA has discovered that the most effective ways to deter student-athletes from wagering on sports includes using a tier approach that involves 1. Coaches; 2. Teammates; 3. NCAA penalties; 4. Pro athlete presentations; and 5. Parents (Paskus \& Derevensky, 2012). The NCAA has also identified an increased need for gambling education programming for student-athletes, particularly in Divisions II and III, where educational programming does not occur with the same frequency as in Division I (Paskus \& Derevensky, 2012). Generally, there are more opportunities for Division I student-athletes to become involved with negative gambling predicaments. Division I student-athletes have higher profiles, oftentimes maintain celebrity-like statuses on their campuses, have access to boosters, and are more at risk for potential problems including being approached by outsiders to share inside information or to participate in point-shaving schemes. The status of many Division I student-athletes often equates more closely to a professional atmosphere than that of a Division II or III student-athlete (Boswell, 2008; Miller, 2012). Based on these facts, Division I athletics departments feel the need to provide more education to student-athletes on the risks of gambling than their Division II and III counterparts (National Collegiate Athletic Association, 2013b).

The purpose of our research was to determine if viewing NCAA educational videos would alter gambling attitudes and behaviors. A secondary purpose was to compare rates of self-reported gambling and gambling attitudes from the NCAA Division II baseball team sample with results reported nationally for NCAADivision II baseball student-athletes.

To measure the incidence of problem gambling among the baseball team members, a research instrument was developed using the South Oaks Gambling Screen (SOGS). An ancillary instrument was structured around key themes and subject topics that are used in the NCAA gambling prevention and education website: dontbetonit.org; and from the results reported in the NCAA Student-Athlete Gambling Behaviors and Attitudes study (NCAA-SAGBA) to create a list of survey questions. The questions were piloted with several experts to establish their clarity, with these foci forming the basis of the study.

Using an experiential approach, we sought to test the effectiveness of NCAAproduced educational videos in altering baseball student-athletes' attitudes toward gambling. Specifically, our research hypothesis $\left(\mathrm{H}_{1}\right)$ stated that student-athletes randomly assigned to view NCAA Don't Bet On It videos will report lower occurrences of progambling attitudes and behaviors than the student-athletes assigned not to view the videos.

The research instrument was also used to compare baseball student-athletes' sports wagering and gambling behaviors with the national averages in Division II baseball. In other words, we anticipated the results of this research paralleling that of previous NCAA self-report studies on gambling. Because of society's increased acceptance of gambling and the propensity of collegiate baseball student-athletes to gamble, this research is important to better understand current gambling attitudes, behaviors, and potential interventions. This study contributes to the literature because it focuses on an area that has been minimally researched. And although gambling and baseball have historically been linked, no known research studies have been conducted specifically on the gambling attitudes and behaviors of Division 
II baseball student-athletes, a demographic that has been identified by the NCAA as one of the most likely to gamble and develop gambling problems (Paskus \& Derevensky, 2012).

\section{Methods}

\section{Participants}

The participants for this study included a convenience sample of 33 college-age male student-athletes (age range, $18-23$ years; mean $=20.2 \pm 1.38$ years) who were members of a NCAA Division II varsity baseball team in the mid-Atlantic region. In academic class standing, 22\% were freshmen, $27 \%$ sophomores, $33 \%$ juniors, and $18 \%$ seniors. Ninety-seven percent of the student-athletes were white, and $3 \%$ described themselves as both white and African-American. Ninety-four percent reported living with other students, $3 \%$ lived with roommates who are not students, and $3 \%$ lived with their parents. The majority of participants $(79 \%)$ reported living in off-campus housing, with the remaining $21 \%$ living in residence halls on campus. When asked to best describe gambling behaviors within their families, $43 \%$ stated that their family does not gamble, $36 \%$ play fantasy sports, $15 \%$ gamble at casinos and $6 \%$ play bingo and other games of chance.

\section{Measures}

South Oaks Gambling Screen. Each study participant completed the South Oaks Gambling Screen (SOGS; Lesieur \& Blume, 1987). The SOGS is a popular measure of gambling-related symptoms and identifies problem and disordered gamblers. According to Stuhldreher, Stuhldreher, and Forrest (2007), the SOGS is the "gold standard" of gambling screens. Participants who score one or less are classified as nonproblem gamblers, participants who score two are classified as having some problems with gambling, and participants who score three or four are classified as problem gamblers. Participants who score five or higher are classified as disordered gamblers. The SOGS has adequate test-retest reliability ( $r=.71$ ) (Lesieur \& Blume, 1987; Stinchfield, 2002). The SOGS also is correlated with DSM-IV diagnostic criteria for pathological gambling in both clinical and generation population samples ( $r=.83$ and $r=.77$ respectively) (Stinchfield, 2002). Stuhldreher et al. (2007) recommends that gambling-related research surveys should use evaluation tools like the SOGS to maintain consistent tracking of trends throughout various settings and populations.

Gambling in Sport Survey. In addition to the SOGS instrument, a second set of survey items titled "The Gambling in Sport Survey" (GSS) was developed using themes and subject topics from the NCAA-SAGBA. The GSS consisted of 26 questions focused on participants' gambling histories, attitudes toward gambling, and knowledge and opinions of NCAA gambling rules and policies. The subjects answered questions published on the GSS using a 5-point Likert scale (strongly disagree / disagree /neutral / agree / strongly agree) to determine their participation in gambling as a member of the baseball team. The GSS has good test-retest reliability $(r=.84)$. 


\section{Procedures}

A Randomized Controlled Trial (RCT) with a pretest-posttest design was conducted. A RCT is considered the gold standard of experimental research. A RCT involves at least two groups of individuals with the same condition, often named the "experimental group" and the "control group." Participants are randomly assigned to either group. The experimental group receives the intervention, while the control group receives an alternative treatment, placebo, or no treatment at all. Both groups are then evaluated at least once to see if any differences exist following the intervention (National Athletic Trainers Association, 2014).

The Institutional Review Board (IRB) of the participating institution approved all aspects of this study. Each subject completed a written consent form before the pretest. All subjects were informed that their participation in this study was voluntary and they could leave at any time. Subjects were also informed that participation in the research study was confidential. The survey did not ask for any information that would identify who the responses belonged to. Subjects were also informed that in the event of any publication or presentation resulting from the research, no personally identifiable information would be shared because their name was in no way linked to their response. This information was confirmed on a consent form. Subjects received no incentives for participating in this study. At the conclusion of the study, all documents were locked in a file by the lead investigator.

The procedure began with all subjects entering the room and checking their name off of a preprinted roster sheet. Both groups were given a pretest GSS questionnaire to establish a baseline measure to analyze before the educational intervention procedure.

Each subject was randomly assigned to a condition based on what color paper they received to complete the questionnaire. Subjects were instructed to choose any seat in the room. To ensure accurate records of both control and experimental group subjects, each group was provided a different color of paper during the pretest. The control group received a yellow copy of paper, while the experimental group received a blue copy. Seventeen subjects received a blue copy of the survey, while 16 received a yellow copy. This process ensured that the researcher could identify which subjects belonged in each group.

The control group exited the room upon completion of the pretest questionnaire. The control group relocated to a lounge area where they watched television, talked among themselves and relaxed under the supervision of an observer. The experimental group remained in the room and watched several brief educational videos, totaling approximately $15 \mathrm{~min}$, with information on NCAA gambling rules, problem gambling, gambling addiction, and treatment practices. This 15 -min timeframe (for the video education intervention) was chosen in an effort to provide as much information on the topic as possible to the student-athletes, while at the same time keeping it brief enough to keep their full viewing attention.

The experimental group received the NCAA online video educational intervention, while the control group did not. Both groups were then administered a posttest after the intervention, and the results of the two groups' responses were compared. The purpose of this design was to recognize any type of changes that may have occurred, and to assess whether those changes were due to the educational intervention program. The pretest questionnaire included questions on demographics, 
individuals' gambling history, NCAA rules and regulations, readiness to change, education intervention, and the SOGS.

The experimental group watched a total of nine videos from the NCAA Don't Bet On It website, dontbetonit.org (See Appendix E). This website was designed as an educational piece for all NCAA student-athletes regarding the risks of sports wagering. In determining which videos to use in this study, the researcher followed the recommended guidelines for use outlined on dontbetonit.org. The website states the following:

Dontbetonit.org is designed to be flexible for you to use. Feel free to skip around sections and pick and choose among the videos and scenarios to share with your audience. However, make sure that in whatever order you select to watch the program, you do review the entirety of the main content and watch at least one video or one scenario when they are offered. The main program content takes only about 15 minutes to view-well worth it to reduce risks to your student-athletes. (NCAA Don't Bet On It, n.d.).

Videos were also selected based on applicability to study subjects, informational significance, and predicted impact on subject attitudes toward gambling. The length of the nine videos totaled approximately $15 \mathrm{~min}$, with several seconds of buffer time in between each to allow for the researcher to load the ensuing video. Total educational intervention time equaled approximately $20 \mathrm{~min}$. Subjects in the experimental group were instructed to not discuss the videos or any information provided to them with the control group subjects before theposttest.

Of the techniques that positively influence male student-athletes not to wager on sports, messages and communications from celebrity athletes ranks fourth (Paskus \& Derevensky, 2012). The NCAA Don't Bet On It videos feature former professional basketball player and current CBS Sports college basketball analyst Clark Kellogg as the host throughout the navigation of the site. The NCAA may have likely used Kellogg as the host due to his celebrity status as a former professional athlete and prominent figure in contemporary college athletics.

At the conclusion of the video intervention, the researcher instructed the control group to reenter the room. Both groups were then administered the posttest questionnaire. The posttest was performed approximately $25 \mathrm{~min}$ after the pretest. The posttest included all the same questions as the pretest, aside from demographic information and the SOGS. It was safely assumed that the gambling education intervention video would not alter the responses to the demographics or SOGS, therefore it was not necessary to include these same questions in the posttest portion of the study.

All subjects then received an informational index card for debriefing. The index card contained information on the NCAA Don't Bet On It website. Subjects were encouraged to visit the Don't Bet On It website for further information on NCAA gambling rules and regulations, gambling risks and consequences, danger signs of gambling, and ways to seek treatment for problem gambling. Other avenues for problem gambling treatment were also included on the index card, including the University Counseling Center, the National Council for Problem Gambling website, and www.ncpgambling.org.

Two weeks following the pretest-posttest day, all subjects returned to complete the posttest questionnaire for a second time. This second posttest was administered 
to test for stability of attitudes over time. At the conclusion of the second posttest, the researcher held an open forum for discussion and questions on the study topic, in which he discussed the study design and outlined some of the significant results from the initial test day. The close of this second posttest marked the end of the study for all subjects.

\section{Data Analysis}

SPSS.22, a commonly used statistical package for the social sciences, was used for the statistical analysis of this study. A Mann-Whitney $U$ test was used to compare the mean difference between the two groups on the pretest and the first posttest. The Mann-Whitney $U$ test compares two independent samples when the data are ordinal (McCrum-Gardner, E, 2007). A 5-point Likert scale (strongly disagree/disagree/neutral/agree/strongly agree) was used as the ordinal scale of measurement in this study.

In addition to comparing the mean scores of the control and experimental groups on the pretest and posttest, the researcher examined if any attitudinal and knowledge changes occurred two weeks after the initial intervention. This was analyzed using the Friedman test, a nonparametric alternative to the one-way ANOVA. The Friedman test is used to test for differences between groups across multiple observation periods when the dependent variable being measured is ordinal (Sheldon, Fillyaw, \& Thompson, 1996). The level of significance was set at $p=<0.05$.

The dependent variable was the gambling attitudes and behaviors of the subjects, measured by the GSS. The independent variable was whether subjects were placed into the control group or the experimental group. The experimental group received a video intervention, while the control group received no intervention. Before the intervention, the two groups were not significantly different at $p \leq .05$ on the SOGS, demonstrating that the groups were equally randomized.

\section{Results}

Subjects in this study participated in sports wagering at rates that mimic the national average for Division II baseball $(9.1 \%$ for test subjects vs. $8.4 \%$ for national average). Results showed that subjects were participating in gambling behaviors. Twenty-nine subjects (88\%) indicated that they had gambled on some level during their lifetime, while $25(76 \%)$ had gambled in the previous year.

The most popular forms of gambling were playing cards for money (48.5\%), bowling/shooting pool/golfing or playing another sport for money (39.4\%), playing the lottery $(27.3 \%)$, and gambling in a casino $(24.2 \%)$. Thus, findings suggest that the majority of the subjects are gambling in some way. Some of the types of gambling, such as gambling in a casino and playing the lottery, are legalized forms of gambling that do not violate NCAA rules. However, 21 subjects $(64 \%)$ indicated that they had participated in gambling activities that violate NCAA rules, such as gambling on sports, playing another sport for money (bowling/shooting pool/ golfing), or gambling on fantasy sports. Appendix A reflects the types of gambling activities that the subjects participated in during the past 12 months.

Data from the SOGS showed the majority of subjects (79\%) indicated that they did not have any problems with gambling. Five respondents (15\%) rated as having some problems with gambling with scores of two on the SOGS. One respondent 
received a score of three and was classified with the potential to develop gambling disorder. Another respondent received a score of five or more (nine) and was therefore classified as a probable disordered gambler.

It was hypothesized that the NCAA Don't Bet On It videos would positively impact attitudes and behaviors. Significant change from the pre scores and post scores (significant at the alpha 0.05 level) were noted on six survey questions in three thematic topic areas: 1) Acceptability/Consequences of Gambling, 2) Gambling Rules, and 3) Skill vs. Luck. Results of the six questions with significant differences are shown in Appendix B. The results to these six questions suggest that the video intervention administered to the experimental group was successful in changing student-athletes' attitudes and knowledge of gambling. In addition, two questions showed moderately significant scores between groups. Results of these two questions are shown in Appendix C.

A second posttest was administered to the groups two weeks following the initial posttest to test for the stability of attitudes over time. One survey question showed statistically significant differences on the second posttest. This suggests that the majority of the attitudinal change that occurred in the initial posttest did not remain stable over the course of two weeks. The one survey question that showed significance differences on the second posttest is outlined in Appendix D.

\section{Discussion}

Gambling continues to evolve as a popular activity among student-athletes, with baseball student-athletes near the top in gambling rates among all sports. This is not surprising considering the increased avenues to gamble, and technology has played a large role in the growing popularity of gambling. Student-athletes have access to a plethora of gambling-related activities. Examples include the use simulated gambling via social media and videogame systems, and the increased popularity of online fantasy sports through companies such as FanDuel and DraftKings.

The media's commercialization of gambling has also contributed to its popularity and social acceptance. Sports networks like ESPN and Fox Sports regularly produce gambling-related content, both on television and online. Fox Sports 1, for example, dedicates a significant portion of its programming to aspects of the sports gambling industry. Similarly, ESPN recently opened a new page on its website, ESPN Chalk, dedicated to sports betting, and has devoted segments of SportsCenter to sports gamblers making their picks on NFL games. Point spreads are also commonly published in newspapers, websites, and television sports programming. The use of technology to gamble, the media's glorification of the activity, and the rise of fantasy sports have all contributed to society's increasing acceptance of gambling as a normalized activity.

Similar to previous research, this study showed that college student-athletes frequently gamble and oftentimes gamble in ways that violate NCAA rules (Paskus \& Derevensky, 2012; Weiss \& Loubier, 2010). While one would anticipate NCAA antigambling rules serving as a deterrent to student-athlete gambling, research suggests otherwise. Several results of this study align with the findings of the 2012 NCAA survey. Over two-thirds (76\%) of the surveyed student-athletes in this study reported wagering something of value over the past year, whereas $57 \%$ of males in the 2012 NCAA survey admitted to gambling in the previous year. Card 
gambling, sports gambling, playing another sport for money (bowling/shooting pool/golfing), and betting on fantasy sports emerged as some of the most popular forms of gambling in this study, much like the NCAA study.

The results of this study suggest that student-athletes prefer to gamble regularly (once a week or more) on games they consider to be skill-based such as card games, sports gambling, bowling, shooting pool, and golf. Previous studies suggest that student-athletes choose to gamble on games of skill because they prefer competitive gambling activities, and they believe they have greater control over the result (Rockey, Beason, \& Gilbert, 2002; Weiss \& Loubier, 2010). Student-athletes are inherently competitive, so it is not surprising that they may gravitate toward gambling activities perceived to involve more skill than luck.

In addition, the results of this study suggest that gambling can lead to major health and well-being issues for some student-athletes. Based on SOGS scores, five respondents $(15 \%)$ were found to have some problems with gambling, while one respondent was classified as a disordered gambler. The American Psychiatric Association (APA) officially recognizes gambling as a valid clinical disorder in the Diagnostic and Statistical Manual of Mental Disorders (DSM-V) (American Psychiatric Association, 2014). While drug and alcohol abuse are commonly associated with collegiate addictive experiences, gambling is also a destructive behavior that affects college student-athletes.

As gambling continues to become more accepted in society, student-athletes may be more likely to believe that gambling is a harmless recreational activity. This idea was confirmed by former University of Maine baseball player Chad White shortly after the 1992 gambling scandal involving 13 suspended Black Bear baseball team members when he stated: "It's been tough without them. This is big. I don't think what they did is worth taking away their college careers for" (Mahoney \& Nash, 1992). In the 2012 NCAA study, 68\% of males and $58 \%$ of females stated that they believed sports wagering was a harmless pastime (Paskus \& Derevensky, 2012). Clearly, many student-athletes do not believe that gambling is a potentially harmful activity. Although some student-athletes may not consider gambling to be damaging, the current Commissioner of Major League Baseball, Rob Manfred, says that "The most fundamental rule in baseball - it has been there forever - it is Rule 21. It prohibits anybody who is on the field from betting on baseball" (Rosecrans, 2015). It is important to recognize that gambling habits developed at younger ages may progress into more severe gambling problems later in life (Ellenbogen et al., 2008).

The NCAA Don't Bet On It website videos provide student-athletes, coaches and administrators with a strategy for educating about the risks of sports wagering. Six questions from this study demonstrated statistically significant differences from the pretest and first posttest, suggesting that the videos were successful in altering some student-athletes' attitudes toward gambling. Clark Kellogg, a former professional basketball player, is prominently featured as the host throughout the NCAA Don't Bet On It website. NCAA research has found that messages from celebrity athletes is one of the most effective ways to positively influence student-athletes' gambling attitudes and behaviors (Paskus \& Derevensky, 2012). Perhaps using a well-recognized professional baseball player rather than a former professional basketball player would have resulted in a more effective attitudinal change among the baseball student-athletes. 
Research suggests that video education is one of the most effective ways to help people learn. This is particularly true for younger generations who have grown up in the age of technological innovation and have an increased understanding and appreciation for technologies such as video communication (Greenberg \& Zanetis, 2012). While video education may be one of the most effective ways to reach today's college-aged student, the NCAA Don't Bet On It videos could have been altered to more properly reflect the sports wagering behaviors of today's student-athletes. For example, fantasy sports were only briefly mentioned in the videos, despite ranking as one of the most popular forms of gambling among student-athletes (Paskus \& Derevensky, 2012). Likewise, the impact of technology on gambling was only temporarily discussed in the videos. Technological enhancements are rapidly changing the way student-athletes gamble and perceive gambling (National Collegiate Athletic Association, 2013a). Based on these research findings, including topics of high relevance in the videos such as fantasy sports and the impact of technology could prove to be more effective in changing the attitudes of the student-athletes.

It is recommended that future studies analyze the impact of video education intervention on student-athletes in a variety of sports, both genders, and across all three divisions of the NCAA. This would allow for comparison on a variety of factors. Future research should also look into adding or changing some of the survey questions to have a stronger foundation of statistically significant attitudinal change among the subjects. Researchers should investigate if any other gambling studies used a RCT with a pretest-posttest design and analyze the effectiveness of the survey questions used in those studies.

Future studies should tailor survey questions toward the areas of highest interest to the subjects. Although the current study did not contain questions directly related to fantasy sports gambling, such as FanDuel and DraftKings, researchers need to investigate this popular and growing trend because it might result in better informed responses. Studies have shown that student-athletes are most likely to play cards or board games for money, bet on games of personal skill, or wager on sports (Huang et al., 2007). This study mirrored previous studies in that respect.

Researchers should also investigate alternative video intervention methods. Showing a variety of gambling educational videos multiple times over the course of several weeks or months could prove more useful in changing attitudes over time. Coaches and athletic administrators could develop a knowledge test following viewing the videos. This study did not conduct a knowledge test, but some type of postintervention assessment could provide valuable data on the effectiveness of a video intervention.

\section{Limitations}

This study provided evidenced-based rationale that video education intervention using the NCAA Don't Bet On It website alters collegiate student-athletes' gambling attitudes. Findings indicated that experimental group subjects knew more about gambling and the risks associated with gambling due to receiving the video education intervention. However, the scope of significant change was limited. Only six of the 26 survey questions used on both the pretest and posttest showed statistically significant attitudinal changes. In addition, only one survey question showed statistically significant differences on the second posttest that was administered two 
weeks after the initial posttest. This demonstrates that the majority of the attitudinal change that occurred did not remain stable over the course of two weeks.

Although the results of this study were based on a small convenience sample, it demonstrated that the NCAA and its member institutions should consider developing more educational programs for student-athletes focused on the dangers of sports wagering. Overall, the demographic of college student-athletes is an important one to study. If nothing is done to educate college student-athletes about the risks involved with gambling activities, gambling problems could impact their grades, athletic success, eligibility, and personal well-being.

Other limitations to this study include participation by student-athletes of only one sport (baseball) and one gender (males). In addition, it is realistic to suspect that self-reported levels of gambling, sports wagering, and related behaviors might be underestimated due to the sensitive nature of the questions asked, particularly with athletic eligibility at stake. Student-athletes may have tried to conceal some of their behaviors in fear that their coaches or athletics administrators would be given the information. Another limitation was the lack of investigating the effectiveness of the video education intervention over a longer time period. The posttest was administered directly after the video was shown and led to significant changes. If the same posttest was administered several days, weeks, or months later it could have led to different results. In addition, two subjects from the experimental group did not participate in the second posttest survey. This could have altered the experimental group results on the Friedman test that analyzed the second posttest data.

\section{Implications}

Given all of the duties and responsibilities of athletics administrators and coaches in today's world of college athletics, gambling prevention often takes a backseat in favor of other issues such as compliance, medical clearances, academic issues, and institutional policies. However, an NCAA gambling violation can tarnish an athletics department's reputation for many years and result in life-changing consequences for student-athletes, coaches, and university leaders.

In college athletics, as in society, gambling is oftentimes not seen as a major issue. At the beginning of each school year, athletics administrators and other support staff typically meet with their student-athletes to go over a variety of key topics, including medical paperwork, academic requirements, and institutional policies, among other items. If the topic of gambling is discussed at all, it is a small footnote among a bevy of other important issues that athletics administrators cover with their student-athletes. Efforts must be made to address the topic of gambling and inform student-athletes that it is a major issue that deserves their attention, not only from the standpoint of protecting the athletics department from gambling-related violations, but also the multitude of public health issues that potentially surround gambling. The potential risks and downfalls of gambling among student-athletes needs to be addressed in the busy lives of athletics directors, coaches and administrators.

Researchers should consider developing innovative ways to involve coaches and administrators in gambling education programs, as well as athletic trainers, equipment managers, and strength and conditioning coaches (Mathner, Martin, Carroll, \& Neal, 2014). NCAA research has found that approximately $40 \%$ of male student-athletes think their coaches consider sports wagering an acceptable 
activity. Furthermore, the NCAA has reported that more than one-third of studentathletes think that coaches would be aware if a team member were gambling on sports (National Collegiate Athletic Association, 2013b). These statistics highlight the importance of including coaches and athletic administrators in educational programming.

Other researchers have also recommended that college campuses implement gambling education and prevention programs that provide information on responsible gambling and warning signs of problem gambling. Because many of the top health-related issues among college students are associated with impulse-control or addiction, researchers have suggested gambling screening for students identified with substance abuse and eating problems (Engwall et al., 2004). Similarly, Stuhldreher et al. (2007) recommended the need for intervention and screening for gambling of students found to participate in other high-risk behaviors. Clearly, researchers believe there is a need for more gambling education on college campuses across the country.

\section{Conclusion}

This research investigated the effectiveness of NCAA educational videos to deter gambling behaviors among intercollegiate baseball players at a Division II university. The differences between the experimental group and control group over several survey questions led us to believe that an effective video education program could work to increase student-athlete awareness of an individual's own gambling behavior and help deter students from participating in potentially illegal behavior that could lead to individual and university penalties and the possibility of individuals becoming problem gamblers.

Gambling among student-athletes is an ongoing and evolving issue that needs to be addressed by college administrators. The NCAA has shown concern on the topic by devoting resources toward research and educational initiatives like the "Don't Bet On It" program. However, the NCAA should not be the only party alarmed about student-athlete gambling. College and university leaders must also concern themselves with this issue, as student-athlete gambling has the potential to harm not only the involved individuals, but the institutions as well. The rising popularity and increased acceptance of gambling activities like fantasy sports provide additional avenues for student-athletes to partake in gambling behaviors. This changing landscape makes it even more critical that college administrators, coaches, and student-athletes become aware and involved in the issue.

\section{References}

American Psychiatric Association. (2013). Highlights of changes from DSM-IV-TR to DSM-5. Retrieved from http://www.dsm5.org/Documents/changes $\% 20$ from $\% 20 \mathrm{dsm}-$ iv-tr\%20to\%20dsm-5.pdf

American Psychiatric Association. (2014). About DSM-5: DSM-5 Development. Retrieved from http://www.dsm5.org/about/pages/default.aspx

Armstrong, J. (2015). More pitchers involved in gambling scandal in Japan baseball. The Associated Press. Retrieved from http://bigstory.ap.org/article/243cb5f92cc9478281c7b0 2c946fc5c5/more-pitchers-involved-gambling-scandal-japan-baseball 
Belson, K., \& Drape, J. (2015). An ad blitz for fantasy sports games, but some see plain old gambling. The New York Times. Retrieved from http://www.nytimes.com/2015/09/17/ sports/football/draftkings-fanduel-fantasy-sports-games.html

Bogdanich, W., Drape, J., \& Williams, J. (2015). Attorney general tells DrafKings and FanDuel to stop taking entries in New York. The New York Times. Retrieved from http:// www.nytimes.com/2015/11/11/sports/football/draftkings-fanduel-new-york- attorneygeneral-tells-fantasy-sites-to-stop-taking-bets-in-new-york.html?_r=1

Boswell, K.J. (2008). Psychological differences between Division I and Division II African American Athletes. (Doctoral dissertation, Union Institute and University). Retrieved from http://pqdtopen.proquest.com/doc/305340484.html?FMT=AI\&pubnum=3299194

Buckstaff, C.D. (2013). Covering the spread: An assessment of amateurism and vulnerability of student-athletes in an emerging culture of sports wagering. Vanderbilt Journal of Entertainment \& Technology Law, 16(1), 133-168.

Burger, T., Dahlgren, D., \& MacDonald, C. (2006). College students and gambling: An examination of gender differences and motivation for participation. College Student Journal, 40(3), 704-714.

Cassuto, L. (2011). Baseball and the business of American innocence. The Chronicle of Higher Education, 57(31), B13-B14.

Chad, N. (2015). The hypocrisy of the NFL's stance on sports gambling is no fantasy. The Washington Post. Retrieved from https://www.washingtonpost.com/sports/fantasysports/the-hypocrisy-of-the-nfls-stance-on-sports-gambling-is-nofantasy/2015/11/01/ cf3b 8c82-7ddb-11e5-afce-2afd1d3eb896_story.html

Cross, M., \& Vollano, A. (1999). The extent and nature of gambling among college studentathletes. Ann Arbor, MI: University of Michigan Department of Athletics.

Drape, J., \& Williams, J. (2015). Scandal erupts in unregulated world of fantasy sports. The New York Times. Retrieved from http://www.nytimes.com/2015/10/06/sports/fandueldraftkings-fantasy-employees-bet-rivals.html?_r=0

Drayer, J., \& Sparvero, E. (2012). Gambling and fantasy: An examination of the influence of money on fan behaviors and attitudes. Sport Marketing Quarterly, 21(3), 159-169 from the Ebscohost database. Retrieved March 31, 2014.

Ellenbogen, S., Jacobs, D., Derevensky, J., Gupta, R., \& Paskus, T. (2008). Gambling behavior among college student-athletes. Journal of Applied Sport Psychology, 20(3), 349-362. doi:10.1080/10413200802056685

Engwall, D., Hunter, R., \& Steinberg, M. (2004). Gambling and other risk behaviors on university campuses. Journal of American College Health, 52(6), 245-255. PubMed doi:10.3200/JACH.52.6.245-256

Figone, A. (2012). Cheating the spread: Gamblers, point shavers, and game fixers in college football and basketball. Urbana, IL: University of Illinois Press.

Fish, M. (2009). Six ex-players charged with conspiracy. ESPN.com. Retrieved from http:// espn.go.com/ncaa/news/story?id=4146980

Florio, M. (2012). NFL prohibits any gambling by officials. Pro Football Talk. Retrieved from http://profootballtalk.nbcsports.com/2012/08/08/nfl-prohibits-any-gamblingby-officials/

Florio, M. (2015). NFL allows players to engage in certain types of gambling. Pro Football Talk. Retrieved from http://profootballtalk.nbcsports.com/2015/06/11/nfl-allowsplayers-to-engage-in-certain-types-of-gambling/

Frisaro, J. (2015). Cosart not found to have bet on baseball. MLB News. Retrieved from http://m. mlb.com/news/article/116204346/jarred-cosart-not-found-to-have-bet-on-baseball

Ginsburg, D. (2004). The fix is in: A history of baseball gambling and game fixing scandals. Jefferson, NC: McFarland \& Company, Inc.

Goldstein, J. (2003). Recent scandals: BC, Tulane and Northwestern. ESPN Classic. Retrieved from http://espn.go.com/classic/s/basketball_scandals_recent.html 
Greenberg, A., \& Zanetis, J. (2012). The impact of broadcast and streaming video in education. Portion Cisco Systems Inc. and portion Wainhouse Research, LLC. Retrieved from http://www.cisco.com/c/dam/en_us/solutions/industries/docs/education/ciscovideowp.pdf

Hohler, B. (2014). When 'Goodfellas' collided with BC basketball. The Boston Globe. Retrieved from https://www.bostonglobe.com/sports/2014/03/15/and-goodfellas-sportsscandal-and-its-lingering-toll/nvlXKiXCYsGpUqBUtg9BRN/story.html

Huang, J., Jacobs, D.F., Derevensky, J.L., Gupta, R., \& Paskus, T.S. (2007). A National Study on Gambling among US College Student-Athletes. Journal of American College Health, 56(2), 93-99. PubMed doi:10.3200/JACH.56.2.93-100

Kludt, T. (2015). DraftKings and FanDuel ads seem to be everywhere on TV because they are. CNN Money. Retrieved from http://money.cnn.com/2015/10/08/media/fandueldraftkings-commercials/index.html

LaBrie, R.A., Shaffer, H.J., LaPlante, D.A., \& Wechsler, H. (2003). Correlates of college student gambling in the United States. Journal of American College Health, 52(2), 53-62. PubMed doi:10.1080/07448480309595725

Lesieur, H., \& Blume, S. (1987). The South Oaks Gambling Screen (SOGS): A new instrument for the identification of pathological gamblers. The American Journal of Psychiatry, 144, 1184-1188. PubMed doi:10.1176/ajp.144.9.1184

Lesieur, H., Cross, J., Frank, M., Welch, M., \& White, C.M. (1991). Gambling and pathological gambling among university students. Addictive Behaviors, 16, 517-527. PubMed doi:10.1016/0306-4603(91)90059-Q

Levinson, M. (2015). Daily fantasy sports growth pushes leagues to regulate players. Bloomberg Business. Retrieved from http://www.bloomberg.com/news/articles/2015-04-01/ daily-fantasy-sports-growth-pushes-leagues-to-regulate-players

Lisk, J. (2015). MLB, NBA, and NHL players cannot play daily fantasy; NFL takes position it's not an issue. Retrieved from http://thebiglead.com/2015/04/10/mlb-nba-and-nhlplayers-cannot-play-daily-fantasy-nfl-takes-position-its-not-an-issue/

Mahoney, L., \& Nash, J. (1992). Three UM athletes reinstated. Bangor Daily News. Retrieved from http://archive.bangordailynews.com/1992/04/23/three-um-athletes-reinstated/

Mathner, R., Martin, C., Carroll, M., \& Neal, T. (2014). Extending sports wagering studies outside of the student-athlete population: NCAA division I athletic trainers' gambling behaviors. Journal of Issues in Intercollegiate Athletics, 7, 431-444.

McCrum-Gardner, E. (2007). Which is the correct statistical test to use? British Journal of Oral \& Maxillofacial Surgery, 46, 38-41. PubMed doi:10.1016/j.bjoms.2007.09.002

Miller, A. (2012). NCAA division I athletics: Amateurism and exploitation. The Sport Journal. Retrieved from http://thesportjournal.org/article/ncaa-division-i-athleticsamateurism-and-exploitation/

Millman, C. (2002). The odds: One season, three gamblers, and the death of their Las Vegas. Cambridge, MA: Da Capo Press.

Moran, M. (1996). Boston College bans 13 football players over bets. The New York Times. Retrieved from http://www.nytimes.com/1996/11/07/sports/boston-college-bans13-football-players-over-bets.html

National Athletic Trainers Association. (2014). Evidence-Based Practice in Athletic Training - Level 1, Part 1. Retrieved from NATA.org.

National Center for Responsible Gaming. (2013). The evolving definition of pathological gambling in the DSM-5. Retrieved from http://blog.ncrg.org/blog/2013/05/evolvingdefinition-pathological-gambling-dsm-5

National Collegiate Athletic Association. (n.d.) Gambling on college sports. Retrieved from http://www.ncaa.org/about/resources/media-center/gambling-college-sports

National Collegiate Athletic Association. (2013a). Latest wagering study shows decrease in gambling activity. NCAA News, 4. 
National Collegiate Athletic Association. (2013b). NCAA Student-Athlete Gambling Behaviors and Attitudes: 2004-2012 Executive Summary. Retrieved from http://www.ncaa. org/sites/default/files/executive_summary_final_may2013.pdf

National Collegiate Athletic Association. (2014). Legislative Services Database. Retrieved from https://web1.ncaa.org/LSDBi/exec/miSearch

National Gambling Impact Study Commission. (1999). National Gambling Impact Study Commission Final Report. Retrieved from http://govinfo.library.unt.edu/ngisc/reports/ fullrpt.html

Don't Bet On It, N.C.A.A. (n.d.). Retrieved from http://www.dontbetonit.org.

Ozanian, M. (2015). Pete Rose and the $\$ 5$ billion sports gambling lie. Forbes / SportsMoney Retrieved from http://www.forbes.com/sites/mikeozanian/2015/06/23/petes-roses5-billion-gambling-lie/

Paskus, T., \& Derevensky, J. (2012). NCAA student-athlete gambling behaviors and attitudes: 2004-2012. NCAA Research. Retrieved from http://www.ncaa.org/sites/default/files/ ncaa_wagering_prelim_may2013_0.pdf

Reib, E.N. (2011). Ante up or fold: What should be done about gambling in college sports? Marquette Sports Law Review, 21(2), 621-640.

Rockey, D.L., Beason, K.R., \& Gilbert, J.D. (2002). Gambling by college athletes: An association between problem gambling and athletes. The Electronic Journal of Gambling Issues. Retrieved from http://www.camh.net/egambling/issue7/index.html.

Rosecrans, T. (2015). Manfred: If you bet on baseball, you'll be banished. Cincinnati.com. Retrieved from http://www.cincinnati.com/story/sports/mlb/reds/2015/04/10/manfredrose-passage-time-changes-situation/25610281/

Seifried, C., Krenzelok, A., Turner, B.A., \& Brett, M. (2009). The prevalence of gambling in college: A review of literature, convenience sample, and recommendations. ICHPERSD Journal of Research, 4(1), 13-20.

Shaffer, H.J., Hall, M.N., \& Vander Bilt, J. (1999). Estimating the prevalence of disordered gambling behavior in the United States and Canada: A research synthesis. American Journal of Public Health, 89(9), 1369-1376. PubMed doi:10.2105/AJPH.89.9.1369

Sheldon, M.R., Fillyaw, M.J., \& Thompson, W.D. (1996). The use and interpretation of the Friedman test in the analysis of ordinal-scale data in repeated measures designs. Physiotherapy Research International: The Journal For Researchers And Clinicians In Physical Therapy, 1(4), 221-228. PubMed doi:10.1002/pri.66

Sheridan, C. (2007). NBA to revamp ref gambling rules; Jackson, Nunn see roles reduced. ESPN.com. Retrieved from http://espn.go.com/nba/news/story?id=3079309

Silver, A. (2014). Legalize and regulate sports betting. The New York Times. Retrieved from http://www.nytimes.com/2014/11/14/opinion/nba-commissioner-adam-silver-legalizesports-betting.html?_r=0

Smith, C. (2012). Why is gambling on fantasy football legal? Forbes. Retrieved from http:// www.forbes.com/sites/chrissmith/2012/09/19/should-gambling-on-fantasy-footballbe-legal/

Stinchfield, R. (2002). Reliability, validity, and classification accuracy of the South Oaks Gambling Screen (SOGS). Addictive Behaviors, 27, 1-19. PubMed doi:10.1016/ S0306-4603(00)00158-1

Stinchfield, R., Hanson, W.E., \& Olson, D.H. (2006). Problem and pathological gambling among college students. New Directions for Student Services, 113, 63-72. doi:10.1002/ Ss. 196

Stuhldreher, W.L., Stuhldreher, T.J., \& Forrest, K. (2007). Gambling as an emerging health problem on campus. Journal of American College Health, 56(1), 75-88. PubMed doi:10.3200/JACH.56.1.75-88

Volberg, R.A. (1996). Prevalence studies of problem gambling in the United States. Journal of Gambling Studies, 12, 111-128. PubMed doi:10.1007/BF01539169 
Weiss, S.M., \& Loubier, S.L. (2010). Gambling habits of athletes and nonathletes classified as disordered gamblers. The Journal of Psychology, 144(6), 507-521. PubMed doi:1 $0.1080 / 00223980.2010 .503248$

Williams, R. J., \& Volberg, R. A. (2012). Population assessment of problem gambling: Utility and best practices. Report prepared for the Ontario Problem Gambling Research Centre and the Ontario Ministry of Health and Long Term Care. April 30, 2012.

\section{Appendix A}

Past-Year Prevalence of Gambling Activities Engaged in by a Sample of Student-Athletes

\begin{tabular}{lccc}
\hline & Not at all & $\begin{array}{c}\text { Less than } \\
\text { once a week }\end{array}$ & $\begin{array}{c}\text { Once a week } \\
\text { or more }\end{array}$ \\
\hline Played cards for money & 51.5 & 39.4 & 9.1 \\
Bet on horses, dogs or other animals & 100 & 0.0 & 0.0 \\
Bet on sports & 87.9 & 9.1 & 3.0 \\
Bet on dice games & 93.9 & 6.1 & 0.0 \\
Gambled in a casino & 75.8 & 24.2 & 0.0 \\
Bet on numbers or lottery & 72.7 & 27.3 & 0.0 \\
Played bingo for money & 81.8 & 18.2 & 0.0 \\
Played the stocks or commodities & 93.8 & 3.1 & 3.1 \\
market & & & 0.0 \\
Played slot machines & 81.8 & 18.2 & 3.0 \\
$\begin{array}{l}\text { Bowled, shot pool, played golf or } \\
\text { other sport for money }\end{array}$ & 60.6 & 36.4 & 0.0 \\
$\begin{array}{l}\text { Played pull tabs or paper games } \\
\text { Other form of gambling not listed }\end{array}$ & 90.9 & 9.1 & 3.1 \\
above & 84.4 & 12.5 & \\
\hline
\end{tabular}

Note. All numbers are percentages. The sample size is 33 participants. 


\section{Appendix B}

\section{Pretest-Posttest Questions Showing Significant Statistical Differences in Gambling Attitudes Between Groups}

\begin{tabular}{|c|c|c|c|c|c|c|c|}
\hline \multirow[b]{2}{*}{ Question } & \multirow[b]{2}{*}{ Group } & \multirow[b]{2}{*}{$\mathbf{N}$} & \multicolumn{2}{|c|}{ Pretest } & \multicolumn{2}{|c|}{ Posttest } & \multirow[b]{2}{*}{ p } \\
\hline & & & M & $S D$ & M & $S D$ & \\
\hline \multicolumn{8}{|c|}{ Thematic Topic: Acceptability/Consequences of Gambling } \\
\hline \multirow{3}{*}{$\begin{array}{l}\text { Sports wagering is acceptable so } \\
\text { long as you wager on a sport other } \\
\text { than the one in which you participate }\end{array}$} & Experimental & 17 & 2.70 & 1.05 & 1.71 & 0.47 & .003 \\
\hline & Control & 16 & 2.63 & 0.96 & 2.56 & 0.89 & \\
\hline & Total & 33 & 2.67 & 0.99 & 2.12 & 0.82 & \\
\hline \multirow{3}{*}{$\begin{array}{l}\text { Gambling on sporting events is a } \\
\text { harmless pastime }\end{array}$} & Experimental & 17 & 2.35 & 0.99 & 2.18 & 0.88 & .006 \\
\hline & Control & 16 & 2.75 & 0.88 & 3.06 & 0.93 & \\
\hline & Total & 33 & 2.55 & 0.91 & 2.61 & 0.99 & \\
\hline \multicolumn{8}{|l|}{ Thematic Topic: Gambling Rules } \\
\hline \multirow{3}{*}{$\begin{array}{l}\text { I could be expelled from school if } \\
\text { caught gambling on sports }\end{array}$} & Experimental & 17 & 3.47 & 1.01 & 4.06 & 0.83 & .019 \\
\hline & Control & 16 & 3.38 & 0.89 & 3.31 & 0.95 & \\
\hline & Total & 33 & 3.42 & 0.94 & 3.70 & 0.95 & \\
\hline \multirow{3}{*}{$\begin{array}{l}\text { Participating in a March Madness } \\
\text { pool with an entry fee and prize } \\
\text { money is a violation of NCAA rules }\end{array}$} & Experimental & 17 & 4.12 & 0.70 & 4.12 & 1.11 & .021 \\
\hline & Control & 16 & 3.63 & 1.15 & 3.44 & 1.03 & \\
\hline & Total & 33 & 3.88 & 0.96 & 3.79 & 1.11 & \\
\hline \multirow{3}{*}{$\begin{array}{l}\text { Participating in a fantasy sports } \\
\text { league with an entry fee and prize } \\
\text { money is not gambling }\end{array}$} & Experimental & 17 & 2.76 & 1.15 & 2.06 & 1.20 & .023 \\
\hline & Control & 16 & 3.19 & 1.42 & 3.00 & 1.21 & \\
\hline & Total & 33 & 2.97 & 1.29 & 2.52 & 1.28 & \\
\hline \multicolumn{8}{|l|}{ Thematic Topic: Skill vs. Luck } \\
\hline \multirow{3}{*}{$\begin{array}{l}\text { Sports wagering is more about skill } \\
\text { and knowledge than luck or chance }\end{array}$} & Experimental & 17 & 3.12 & 0.99 & 2.41 & 1.33 & .050 \\
\hline & Control & 16 & 2.94 & 0.85 & 3.13 & 0.89 & \\
\hline & Total & 33 & 3.03 & 0.92 & 2.76 & 1.17 & \\
\hline
\end{tabular}

Note. N: number of subjects; M: mean; SD: standard deviation; $\mathrm{p}$ is significant at <.05; A 5-point Likert scale was used for the survey (strongly disagree/disagree/neutral/agree/strongly agree) 


\section{Appendix C}

\section{Pretest-Posttest Questions Showing Moderately Statistical Differences in Gambling Attitudes Between Groups}

\begin{tabular}{|c|c|c|c|c|c|c|c|}
\hline \multirow[b]{2}{*}{ Question } & \multirow[b]{2}{*}{ Group } & \multirow[b]{2}{*}{$\mathbf{N}$} & \multicolumn{2}{|c|}{ Pretest } & \multicolumn{2}{|c|}{ Posttest } & \multirow[b]{2}{*}{$p$} \\
\hline & & & M & $S D$ & M & $S D$ & \\
\hline \multirow{3}{*}{$\begin{array}{l}\text { I believe the NCAA should remove } \\
\text { eligibility for student-athletes who } \\
\text { gamble on sports }\end{array}$} & Experimental & 17 & 2.59 & 1.18 & 2.94 & 0.97 & .085 \\
\hline & Control & 16 & 2.31 & 1.08 & 2.31 & 1.01 & \\
\hline & Total & 33 & 2.45 & 1.12 & 2.64 & 1.03 & \\
\hline \multirow{3}{*}{$\begin{array}{l}\text { I am more likely to be successful } \\
\text { gambling on sports because I'm an } \\
\text { athlete }\end{array}$} & Experimental & 17 & 2.35 & 0.86 & 2.12 & 1.36 & .088 \\
\hline & Control & 16 & 2.56 & 1.03 & 2.56 & 0.89 & \\
\hline & Total & 33 & 2.45 & 0.94 & 2.33 & 1.16 & \\
\hline
\end{tabular}

Note. N: number of subjects; M: mean; $S D$ : standard deviation; $\mathrm{p}$ is significant at <.05; A 5-point Likert scale was used for the survey (strongly disagree/disagree/neutral/agree/strongly agree)

\section{Appendix D}

Second Posttest Questions Showing Significant Statistical Differences in Experimental Group Gambling Attitudes Over Time

\begin{tabular}{llcccc}
\hline Question & Test & N & M & SD & p \\
\hline Sports wagering is acceptable so long as you & Pretest & 15 & 2.60 & 1.05 & .003 \\
wager on a sport other than the one in which you & Posttest 1 & 15 & 1.67 & 0.49 & \\
participate & Posttest 2 & 15 & 2.00 & 0.65 & \\
\hline
\end{tabular}

Note. N: number of subjects; M: mean; SD: standard deviation; $\mathrm{p}$ is significant at <.05; A 5-point Likert scale was used for the survey (strongly disagree/disagree/neutral/agree/strongly agree) 